\title{
Cardiovascular Death in the Regional Hospital of Koudougou
}

\author{
Koudougou Jonas Kologo',2, Relwendé Aristide Yaméogo ${ }^{3}$, Joel Bamouni4, Stéphane Balima², \\ Georges Rosario Christian Millogo, ${ }^{1,2}$, Patrice Zabsonré ${ }^{1,2}$
}

\author{
${ }^{1}$ University Department of Medical Science (UFR/SDS)/University Ouaga1 Professor Joseph KI-ZERBO, Ouagadougou, Burkina Faso \\ ${ }^{2}$ Cardiology Department of University Hospital Yalgado Ouédraogo, Ouagadougou, Burkina Faso \\ ${ }^{3}$ Medical Department of Regional Hospital, Koudougou, Burkina Faso \\ ${ }^{4}$ Medical Department of Regional Hospital, Ouahigouya, Burkina Faso \\ Email: yraristide@hotmail.fr.
}

How to cite this paper: Kologo, K.J., Yaméogo, R.A., Bamouni, J., Balima, S., Millogo, G.R.C. and Zabsonré, P. (2016) Cardiovascular Death in the Regional Hospital of Koudougou. Open Access Library Journal, 3: e3179.

http://dx.doi.org/10.4236/oalib.1103179

Received: October 27, 2016

Accepted: November 15, 2016

Published: November 18, 2016

Copyright () 2016 by authors and Open Access Library Inc.

This work is licensed under the Creative Commons Attribution International License (CC BY 4.0).

http://creativecommons.org/licenses/by/4.0/ c) (i) Open Access

\begin{abstract}
Cardiovascular diseases actually are a real public health concern all over the world and more specifically in the developing countries. The aim of this study was to analyze the causes and factors associated to deaths due to cardiovascular diseases in medicine and medical emergencies departments at the Regional Hospital (RH) of Koudougou to contribute to treatment improvement. This study was a retrospective and descriptive study conducted over a period of 12 months from January 1st 2014 to December 31st, 2014. This study took place in medicine and medical emergencies departments within the Regional Hospital of Koudougou. We have recorded 282 deceased persons. We have selected 275 deceased persons according to our inclusion criteria. Deaths due to cardiovascular pathologies accounted for 73 cases corresponding to $26.55 \%$. Sex ratio was estimated at 1.8 . Patients' average age was estimated at $62 \pm 17.6$ years. Forty patients corresponding to $54.8 \%$ were referred and $80 \%$ of them came from health and social promotion centers. Strokes representing $32.8 \%$ were the hypotheses mentioned upon admission. State of shock represented $32.8 \%$ of the immediate causes of death. Sixty-four point four percent of patients had high blood pressure as the most frequent initial death cause (47 cases).Thirty five cases of premature deaths, corresponding to $47.9 \%$ were observed. Cardiovascular diseases are a real public health concern in our countries undergoing an epidemiological transition. Mortality related to these diseases in Koudougou $\mathrm{RH}$ has been widely dominated by high blood pressure. This mortality can be reduced through preventive actions meant for the population including a reorganization of health system and hospital services to improve care quality.
\end{abstract}

\section{Subject Areas}

Cardiology 


\section{Keywords}

Causes of Death, Cardiovascular Disease, Mortality, Koudougou

\section{Introduction}

Nowadays, cardiology domain has undergone progress. This includes always providing more remedies or preventive solutions to allow human beings to live longer and enjoy a better living. Notwithstanding, cardiovascular diseases keep on causing deaths [1]. They actually are a real public health concern all over the world and more specifically in the developing countries. This is due to their high prevalence and more particularly their high mortality rate. They represent a heavy burden for society and bring about great costs to the health system. Besides, these diseases are the first cause of mortality all over the world [2]. According to WHO, these affections in 2011 have caused the death of 16.7 million persons all over the world among which $29 \%$ occurred before 60 years. These diseases would cause the death of 23.3 million persons in 2030 if no action is undertaken. Moreover, they are the first cause of death among the women over 65 years old. As for the macroeconomic domain, cardiovascular diseases take a heavy toll on economies of the developing countries up to $6.7 \%$ of their GDP. By 2025, the developing countries (DC) would lose 7000 billion Dollars US for the treatment of non-transmissible diseases against 170 billion Dollars US meant for prevention [3]. These figures are inevitably expected to rise with an ageing population, the increasing urbanization and adoption of new eating habits [4]. Actions need to be rapidly undertaken in order to stop this evolution [5]. A study conducted in the cardiology department of University Hospital-Yalgado Ouédraogo in 2013 revealed that the mortality rate was estimated at $13.2 \%$ with high blood pressure as the main cause of death among which $46.1 \%$ and $59.4 \%$ of patients were under 65 years old [6]. Mortality statistics are the most reliable database to measure the scope of health issues within a country. Death causes are commonly used to guide and assess actions and researches in public health sector [7]. This is the reason why we intend to analyze the causes and factors associated to deaths due to cardiovascular diseases in medicine and medical emergencies departments at the Regional Hospital (RH) of Koudougou to contribute to treatment improvement.

\section{Methodology}

This dealt with a retrospective and descriptive study conducted over a period of 12 months from January 1st 2014 to December 31st, 2014. This study took place in medicine and medical emergencies departments within the $\mathrm{RH}$ of Koudougou.

The study has taken into account all the patients suffering from a cardiovascular disease and who died in medicine and medical emergencies departments during the survey period. We have reviewed all the deceased patients' clinical records in medicine and medical emergencies departments of Koudougou RH. 
The following were considered in the study: all the patients having clinical records who died in the medicine and medical emergencies departments at Koudougou RH during the study period.

All the patients who died at their arrival at the medical emergencies of Koudougou $\mathrm{RH}$ during the study period have not been taken into account.

Data have been collected from: entry and output records, patients' clinical records and an individual form of pre-established collection.

Information was collected using clinical records including treatment and hospitalization registers of the deceased patients in the medical emergencies and medicine departments during our study period.

Data were reviewed through the French version of the software Epi-info 3.5.3. KhiDeuxand Fischer test have been used as statistical tests. The test was significant if $p<$ 0.05 .

This investigation was approved by the local Ethics Committee of the Hospital. Data confidentiality was considering when collecting data, and data anonymity has been respected.

\section{Results}

\subsection{Epidemiological and Socio-Demographics Aspects}

From January 1st to December 31st, 2014, 1795 patients was admitted in the department of medical emergency. We have recorded 282 deceased persons in the departments of medical emergency $(n=219)$ and general medicine $(n=63)$ of RH Koudougou. We have selected 275 deceased persons according to our inclusion criteria. Seven patients were excluded (five patients death at arrival and two medical records was not found). Deaths due to cardiovascular pathologies accounted for 73 cases corresponding to $26.6 \%$. Deaths were registered at the level of medical emergencies for 63 cases corresponding to $86.3 \%$ against 10 cases corresponding to $13.7 \%$ in medicine department.

Sex ratio was estimated at 1.8 . Forty-seven patients corresponding to $64.4 \%$ were male against 26 females corresponding to $35.6 \%$. Thirty-six patients were living in Koudougou, corresponding to $49.3 \%$ and 37 were living out of the town corresponding to $50.7 \%$.

Patients' average age was estimated at $62 \pm 17.6$ years with extremes reaching 25 and 98 years. Patients over 65 years accounted for 35 cases corresponding to $47.9 \%$. Men's average age was $61.1 \pm 16.6$ years with extremes reaching 26 and 98 years and that of women was estimated at $63.5 \pm 19.4$ years with extremes reaching 25 and 94 years. The difference between the average age of men and women was not significant $(p=0.5)$. Figure 1 shows distribution of patients deceased according to age range.

\subsection{Clinical Aspects of the Deceased Patients}

Forty patients corresponding to $54.8 \%$ were referred and $80 \%$ of them came from health and social promotion centers. The Table 1 shows distribution of the deceased patients according to their admission method. 


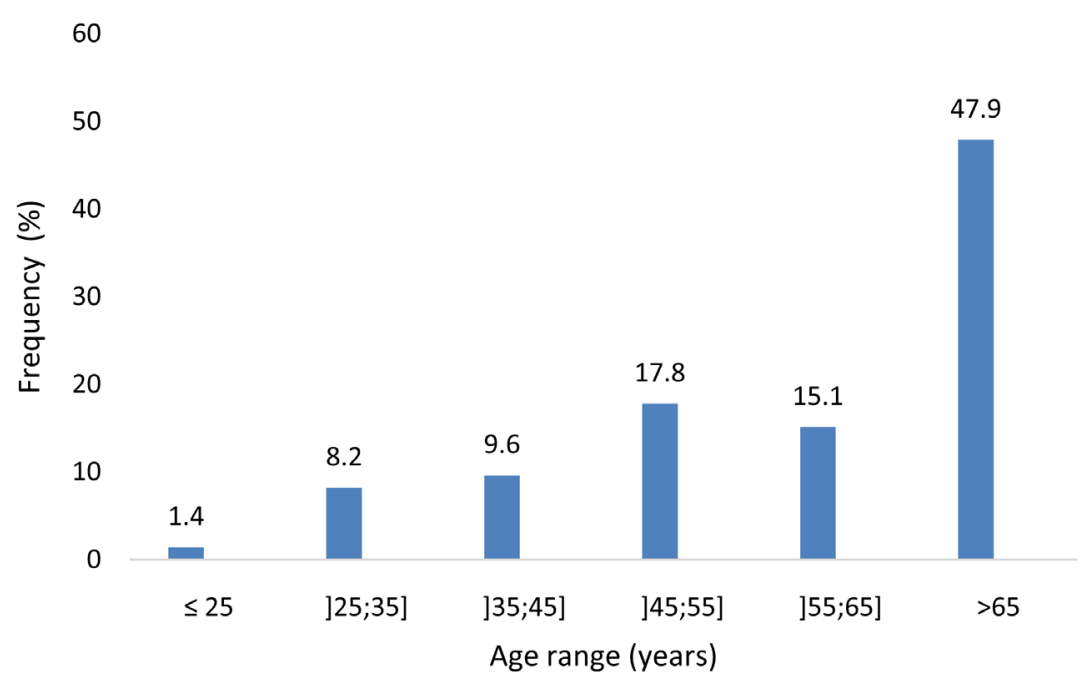

Figure 1. Distribution of patients deceased according to age range.

Table 1. Distribution of the deceased patients according to their admission method.

\begin{tabular}{ccc}
\hline & Frequency & Percentage (\%) \\
\hline Direct admission & 33 & 45.2 \\
Referral & 40 & 54.8 \\
Transfer & 0 & 0 \\
Total & 73 & 100 \\
\hline
\end{tabular}

Twenty four (24) patients had previous medical history of high blood pressure (32.8\%); four had diabetes history $(5.5 \%)$. Seven patients $(9.6 \%)$ have been previously hospitalized.

Patients went for consultation in a health facility on an average of $3.3 \pm 3.4$ days with extremes of 1 and 14 days; others went to RH on an average of $5.5 \pm 12.8$ days with extremes of one and 90 days upon the symptomatology start.

Strokes representing $32.8 \%$ were the hypotheses mentioned upon admission. The Table 2 shows the distribution of diagnosis upon patients' admission.

State of shock represented $32.8 \%$ of the immediate causes of death (concerning 24 cases) and heart failure represented $15.1 \%$ (11 cases). Table 3 shows the distribution of immediate causes of death.

Sixty-four point four percent of patients had high blood pressure as the most frequent initial death cause (47 cases). The following table shows the distribution of patients per initial causes. The Table 4 shows the distribution of initial causes of death.

The average duration for hospitalizing patients was $2.7 \pm 2.6$ days with extremes of one and 15 days.

\subsection{Cases of Premature Death}

Thirty five cases of premature deaths, corresponding to $47.9 \%$ were observed. The total 
Table 2. Distribution of diagnosis upon patients admission.

\begin{tabular}{ccc}
\hline & Frequency & Percentage (\%) \\
\hline Stroke & 24 & 32.8 \\
High blood pressure & 15 & 20.5 \\
Dilated cardiomyopathy & 11 & 15 \\
Pulmonary embolism & 7 & 9.6 \\
Pulmonary disease & 7 & 9.6 \\
Acute kidney failure & 3 & 4.1 \\
Stroke recurrence & 2 & 2.8 \\
Post-partum cardiomyopathy & 1 & 1.4 \\
Keto-acidosis coma & 1 & 1.4 \\
Chronic pulmonary heart disease & 1 & 1.4 \\
Thrombophlebitis & 1 & 1.4 \\
Total & 73 & 100 \\
\hline
\end{tabular}

Table 3. Distribution of 73 patients deceased per immediate causes of death.

\begin{tabular}{ccc}
\hline & Frequency & Percentage (\%) \\
\hline State of shock & 24 & 32.8 \\
Heart failure & 11 & 15.1 \\
Acute pulmonary oedema & 9 & 12.3 \\
Toxic shock & 8 & 10.9 \\
Stroke & 4 & 5.5 \\
Metabolic disorder & 4 & 5.5 \\
Severe anemia & 3 & 4.1 \\
Pleurisy & 3 & 4.1 \\
Decubitus complications & 2 & 2.8 \\
Convulsions & 2 & 2.8 \\
Cerebral herniation & 2 & 2.8 \\
Chest pains & 1 & 1.4 \\
Total & 73 & 100 \\
\hline
\end{tabular}

Table 4. Distribution of 73 deceased patients per initial death causes.

\begin{tabular}{ccc}
\hline & Frequency & Percentage (\%) \\
\hline High blood pressure & 47 & 64.4 \\
Dilated cardiomyopathy & 13 & 17.7 \\
Pulmonary embolism & 9 & 12.3 \\
Post-partum cardiomyopathy & 1 & 1.4 \\
Stroke & 1 & 1.4 \\
Chronic pulmonary heart disease & 1 & 1.4 \\
Thrombophlebitis & 1 & 1.4 \\
Total & 73 & 100 \\
\hline
\end{tabular}


number of life years lost was estimated at 638 years corresponding to an average of 18.2 years. Males were predominant with a sex ratio estimated at 2.1. The average age of the premature deaths was estimated at $18.2 \pm 11.4$ years. State of shock was the first cause of death for $45.7 \%$ of cases and high blood pressure was the initial cause of death for 62.8\%. 18 cases corresponding to $51.4 \%$ had acute pathologies. The Table 5 and Table 6 show distribution of premature deaths cases according to immediate causes of death and initial causes of death.

\section{Discussion}

In our study, the mortality rate due to cardiovascular diseases was estimated at $26.5 \%$. In 1998, Sedego in Burkina Faso had found a mortality rate of 21.3\% [8]. Parkouda and Yaméogo in Burkina Faso respectively reported a mortality rate of $15.8 \%$ in 2010 and 13.2\% in University Hospital Yalgado Ouédrago [6] [9]. It worth noticing that the technical unit of Koudougou RH is very limited concerning diagnosis and therapeutic means. Besides, in most cases medicine and emergencies departments are managed by general practitioners. So, there is the need to link delay in consultation and late diagnosis of cardiovascular diseases to complicated stage. The average age in our study was estimated at 62 years. In the developed countries like France, the average age of deaths related to cardiovascular diseases (CVD) was 80 years [10]. World Health Organization (WHO) affirmed that nearly half of deaths related to CVD in the developing countries occurred before 70 years in 1990 [10]. The persistence of this status after more than two decades shows the failure of health policies conducted in such countries.

Table 5. Distribution of premature deaths cases according to death immediate causes.

\begin{tabular}{ccc}
\hline & Frequency & Percentage (\%) \\
\hline State of shock & 16 & 45.7 \\
Heart failure & 7 & 20 \\
Acute pulmonary oedema & 6 & 17.2 \\
Stroke & 4 & 11.4 \\
Anemia & 2 & 5.7 \\
Total & 35 & 100 \\
\hline
\end{tabular}

Table 6. Distribution of premature deaths cases according to initial death causes.

\begin{tabular}{ccc}
\hline Initial causes & Numbers & Percentage (\%) \\
\hline High blood pressure & 22 & 62.8 \\
Dilated cardiomyopathy & 8 & 22.8 \\
Pulmonary embolism & 4 & 11.5 \\
Post-partum cardiomyopathy & 1 & 2.9 \\
Total & 35 & 100 \\
\hline
\end{tabular}


CVD has brought about premature deaths in $47.9 \%$ of cases in our study with 638 life years lost. In African countries, more than half of deaths per cardiovascular diseases occur among the persons aged between 30 and 69 years, an age beyond 10 years or further below the equivalent group in Europe and Northern America [11]. These deaths will increase throughout time within our context along with premature deaths and significant life years lost if no action is undertaken.

Patients in our study had a consultation in a health facility other than the RH in an average deadline of 3.3 days upon the symptomatology start. This time limit was 5.5 days for those patients received at the RH. Bertrand has made the same observation in 2006 as he found an average consultation time limit estimated at 6.8 days in Sub-Saharan African [12]. Patients did not go to consultation upon the disease outward signs. Several factors could explain the long consultation deadline: the lack of resources to guarantee the funding of first care when being admitted at the emergencies department; the hope to recover spontaneously; the organization of health system requiring the systematic passage to CSPS (primary cares centers), to CMA (medical center with surgical antenna) with and towards the RH. This extends patient's pathway and favors self-medication and sociocultural factors.

Diagnoses mentioned while admitting patients were: stroke and stroke recurrence for $35.5 \%$ of cases, high blood pressure for $20.5 \%$, dilated cardiomyopathy for $15 \%$ cases. Bertrand has observed comparable proportions in Western Africa [12]. Stroke, high blood pressure and cardiomyopathies are the main cardiovascular diseases having a high mortality rate. In 2012 [13], high blood pressure had a prevalence of $30 \%$ in Burkina Faso. This is a major risk factor often unknown by more than $60 \%$ of cases. Less than $30 \%$ of persons suffering from high blood pressure are followed-up [14]. High blood pressure silently evolves towards complications such as stroke and cardiomyopathies.

State of shock and heart failure respectively estimated at $32.8 \%$ and $15.1 \%$ of cases were the immediate death causes in our survey. We notice that the immediate death cause of most deaths was a state of shock directly or indirectly by heart failure and acute pulmonary oedema. Yaméogo' study in 2013 in Burkina Faso showed the state of shock as the immediate death causes due to CVD in $65.7 \%$ of cases [6]. This can be explained by the fact that the majority of cardiac pathologies would evolve in a long term towards a state of shock by deactivating the cardiac pump. This probably explains the late consultations at complicated stages along with life-threatening emergencies.

High blood pressure was the initial death cause of $64.4 \%$ of patients. Our outcomes can be superimposed to Yameogo's at the University Hospital Yalgado Ouédraogo who had observed a predominance of hypertensive cardiac diseases as regards deaths resulting from cardiovascular diseases (46.1\%) [6]. A late diagnosis as well as inadequate treatment are factors bringing patients with complicated stages to emergencies, even with critical emergencies [15] [16]. Mortality resulting from cardiovascular diseases in most cases can be avoided by means of a primary prevention by raising population awareness to recognize and fight against risks factors, and secondary prevention through 
diagnosis and early treatment. High blood pressure is the main risk factor. Its late diagnosis and inappropriate treatment could be the reason for its significant mortality rate.

\section{Conclusion}

Cardiovascular diseases are a real public health concern in our countries undergoing an epidemiological transition. Mortality related to these diseases in Koudougou RH has been widely dominated by high blood pressure. Patients not respecting their therapy, the late consultation and the lack of qualified staff are factors likely to explain the high mortality due to cardiovascular diseases. This mortality can be reduced through preventive actions meant for the population including a reorganization of health system and hospital services to improve care quality.

\section{References}

[1] WHO (2016) Cardiovascular Diseases (CVDs). http://www.who.int/entity/cardiovascular diseases/en/index.html

[2] OMS (2016) Cardiovascular Diseases. http://www.who.int/mediacentre/factsheets/fs317/fr/

[3] WHO (2016) Global Status Report on Non-Communicable Diseases 2010. http://www.who.int/nmh/publications/ncd report2010/en/

[4] Mendis, S., Lindholm, L.H., Mancia, G., Whitworth, J., Alderman, M., Lim, S., et al. (2007) World Health Organization (WHO) and International Society of Hypertension (ISH) Risk Prediction Charts: Assessment of Cardiovascular Risk for Prevention and Control of Cardiovascular Disease in Low and Middle-Income Countries. Journal of Hypertension, 25, 1578-1582. https:/doi.org/10.1097/HJH.0b013e3282861fd3

[5] OMS (2016) Fight against Cardiovascular Diseases: Strategic Priorities. http://www.who.int/cardiovascular diseases/priorities/fr/

[6] Yameogo, A.R., Mandi, G., Millogo, G., Samadoulougou, A. and Zabsonre, P. (2014) Assessing causes of death in the Cardiology Department of Yalgado Ouédraogo University Hospital. The Pan African Medical Journal, 19, 155. https:/doi.org/10.11604/pamj.2014.19.155.5286

[7] Sibai, A. (2004) Mortality Certification and Cause-of-Death Reporting in Developing Countries. Bulletin of the World Health Organization, 82, 83.

[8] Sédégo, B. (1998) Hospital Based Cardiovascular Morbi-Mortality. Medicine Thesis, University of Ouagadougou, Burkina Faso.

[9] Parkouda, A. (2010) Cardiovascular Morbidity and Mortality in the Department of Cardiology at the University Hospital Yalgado Ouédraogo. Medecine Thesis, University of Ouagadougou, Burkina Faso.

[10] Damorou, F., Baragou, S., Pio, M., Afassinou, Y.M., N'da, N.W., Pessinaba, S., et al. (2014) Hospital Based Morbidity and Mortality from Cardiovascular Diseases in Tropical Areas: Example of a Hospital in Lomé (Togo). The Pan African Medical Journal, 17, 62. https:/doi.org/10.11604/pamj.2014.17.62.2237

[11] Nethononda, M.R., Essop, M.R., Mbewu, A.D. and Galpin, J.S. (2004) Coronary Artery Disease and Risk Factors in Black South Africans-A Comparative Study. Ethnicity \& Disease, 14, 515-519.

[12] Bertrand, E., Muna, W.F.T., Diouf, S.M., Ekra, A., Kane, A., Kingue, S., et al. (2006) Cardi- 
ovascular Urgencies in Sub-Saharan Africa. Arch Mal Coeur Vaiss, 99, 1159-1165.

[13] WHO (2016) Burkina Faso. WHO. http://www.who.int/countries/bfa/fr/

[14] Addo, J., Smeeth, L. and Leon, D.A. (2007) Hypertension in Sub-Saharan Africa: A Systematic Review. Hypertension, 50, 1012-1018.

https:/doi.org/10.1161/HYPERTENSIONAHA.107.093336

[15] Lengani, A., Samadoulougou, A. and Cissé, M. (2000) Renal Impairement in the Hypertensive Morbidity from Adult in Burkina Faso. Arch Mal Coeur, 93, 1053-1057.

[16] Yameogo, N.V., Samadoulougou, A., Millogo, G., Kologo, K.J., Kombassere, K., Toguyeni, B., et al. (2012) Delays in the Management of Acute Coronary Syndromes ST Segment Elevation in Ouagadougou and Factors Associated with an Extension of These Delays: A Cross-Sectional Study about 43 Patients in the CHU Yalgado Ouédraogo. The Pan African Medical Journal, 13, 90.

Submit or recommend next manuscript to OALib Journal and we will provide best service for you:

- Publication frequency: Monthly

- 9 subject areas of science, technology and medicine

- Fair and rigorous peer-review system

- Fast publication process

- Article promotion in various social networking sites (LinkedIn, Facebook, Twitter, etc.)

- Maximum dissemination of your research work

Submit Your Paper Online: Click Here to Submit

Or Contact service@oalib.com 